(II) Nordic Council

of Ministers

Arctic Business Analysis

\title{
Entrepreneurship and Innovation
}

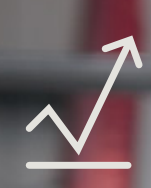




\section{Arctic Business Analysis}

Entrepreneurship and Innovation

ANP 2018:705

ISBN 978-92-893-5334-2 (PRINT)

ISBN 978-92-893-5335-9 (PDF)

ISBN 978-92-893-5336-6 (EPUB)

http://dx.doi.org/10.6027/ANP2018-705

() Nordic Council of Ministers 2018

Layout: Bjørn Ortmann

Cover Photo: Mads Pihl / Visit Greenland

Print: Rosendahls

Printed in Denmark

\section{Nordic co-operation}

Nordic co-operation is one of the world's most extensive forms of regional collaboration, involving Denmark, Finland, Iceland, Norway, Sweden, the Faroe Islands, Greenland, and Åland.

Nordic co-operation has firm traditions in politics, the economy, and culture. It plays an important role in European and international collaboration, and aims at creating a strong Nordic community in a strong Europe.

Nordic co-operation seeks to safeguard Nordic and regional interests and principles in the global community. Shared Nordic values help the region solidify its position as one of the world's most innovative and competitive.

\section{Nordic Council of Ministers}

Nordens Hus

Ved Stranden 18

DK-1061 København K

www.norden.org

Download Nordic publications at www.norden.org/nordpub 


\section{Arctic Business Analysis}

\section{Entrepreneurship and Innovation}

$\underline{v}$

$\sqrt{ }$ Entrepreneurship and Innovation

(4) Creative and Cultural Industries

$\oint$ PPPs and Business Cooperation

D Bioeconomy 


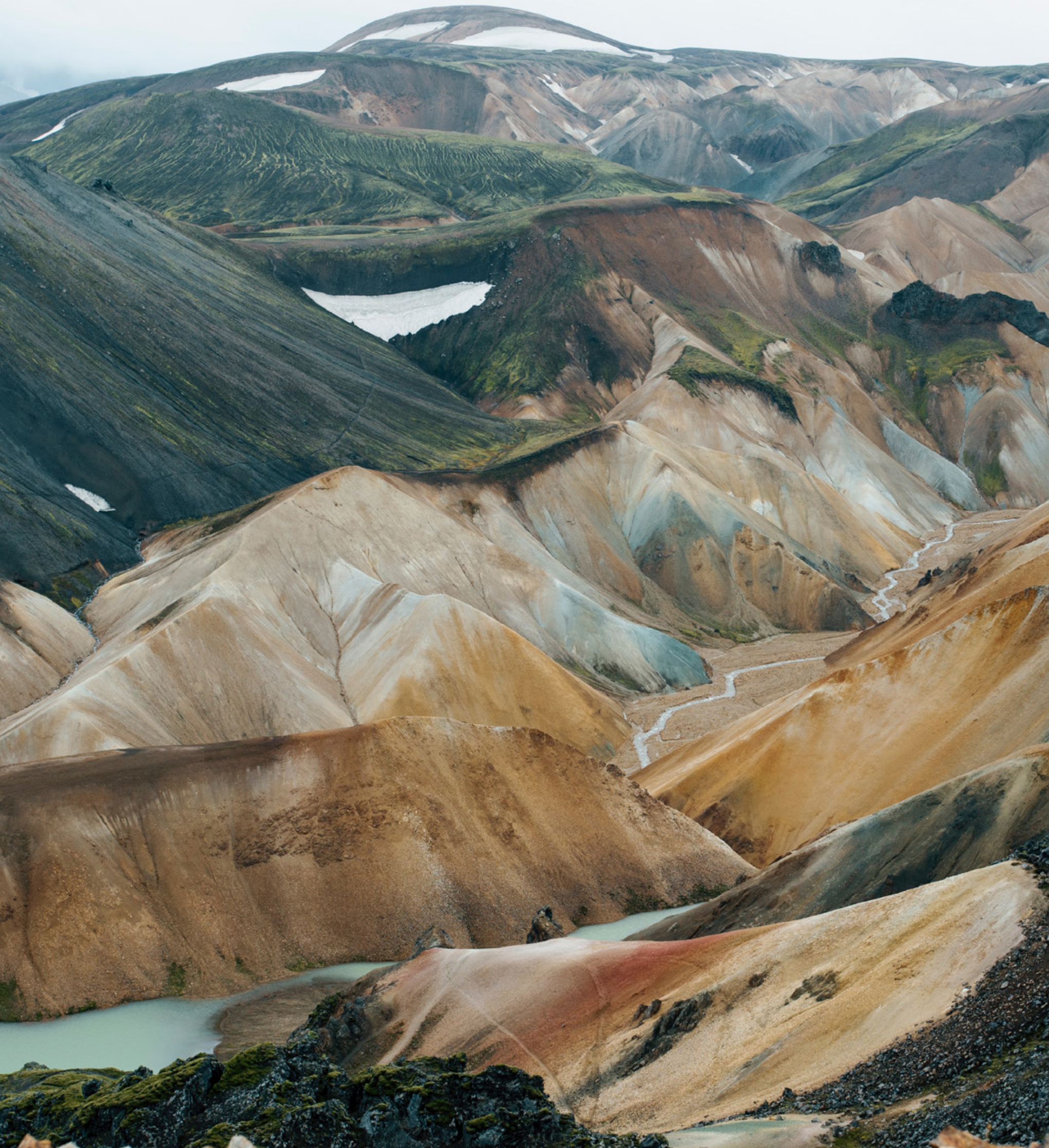

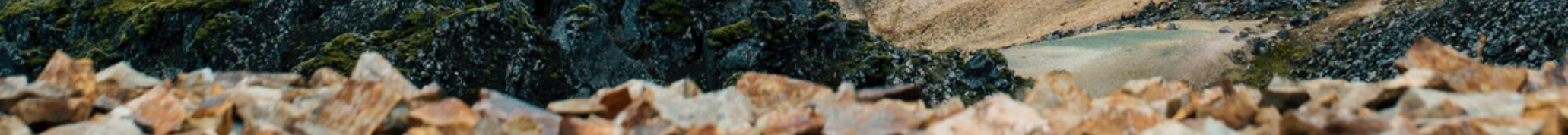

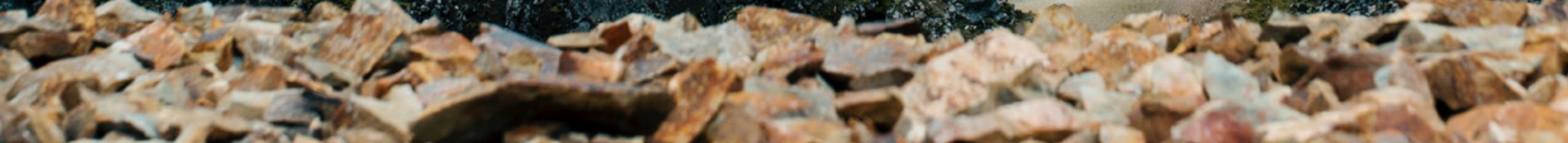

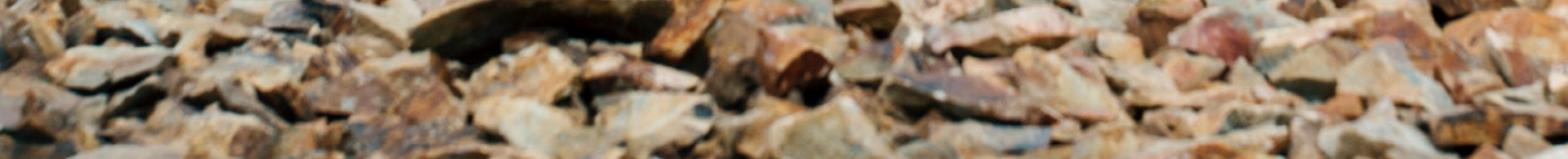




\section{CONTENTS}

$\begin{array}{ll}\text { 1. Introduction } & 7\end{array}$

2. Background

3. Executive Summary of the Arctic Business

Analysis

4. The Nordic Arctic Business Environment:

Entrepreneurship and Innovation

4.1 Mapping of economic activities and policies

4.2

Drivers and enablers of business development

4.3

Recommendations

5. Cross-cutting issue across the Arctic Business

Analysis

6. Methodology

Bibliography

Endnotes 
of sustainable economic development in the Arctic as the logical next step in the work in and for the Arctic. Sustainable development focuses on a balance between economic, social, and ecological dimensions, and aims to ensure that the needs of the present generation are met without compromising future generations' ability to meet their own needs. ${ }^{1}$ As such, promoting sustainable economic development in the Nordic Arctic requires an understanding of the region's business environment and policy incentives, as well as the identification of opportunities for unlocking the Nordic Arctic economic potential, and the development of practical enablers to achieve this end - to the benefit of the entire Arctic. With this perspective in mind, the Nordic Council of Ministers, in collaboration with the Arctic Economic Council, has commissioned the consortium of Voluntas Advisory and the Confederation of Danish Industry (DI) to conduct this Arctic Business Analysis.

The Arctic Business Analysis covers the areas of Entrepreneurship and Innovation, Public-Private Partnerships (PPPs) and Business Co-operation, Bioeconomy, and Creative and Cultural Industries. Each area is covered in a separate publication. This report presents the findings for PPPs and Business Co-operation. The executive summary presents the findings across the four areas of the Arctic Business Analysis.

\section{Nordic Council of Ministers}

The Arctic Business Analysis revolves around opportunities to promote sustainable economic development within the Nordic co-operation, specifically the Nordic Council of Ministers (NCM), as well as other Nordic Arctic stakeholders. It is therefore important to understand NCM's Arctic priorities and its organisational structure.

NCM is the official body for Nordic intergovernmental co-operation. The overall responsibility for this co-operation officially lies with the Nordic Prime Ministers. In practice, the Ministers for Nordic Co-operation, on behalf of the Prime Ministers, assume responsibility for the co-ordination of inter-governmental co-operation. Besides the Ministers for Nordic Co-operation, NCM consists of 10 ministerial councils (MRs) that cover different sectors and are supported by 16 committees of senior officials (EK). The work in the Minister Councils is handled within the Nordic Council of Ministers' Secretariat with a Secretary General responsible for the day-to-day operations of the intergovernmental co-operation and its 12 Nordic institutions and 3 Baltic offices.

NCM has since 1996 had an Arctic co-operation programme. A new Arctic co-operation programme, "Nordic Partnerships for the Arctic" for 2018-2021 will enter into force by 1 January 2018. The overall aim is to promote sustainable development in the Arctic with regards to the four themes of 1 ) peoples; 2 ) planet; 3 ) prosperity; and 4) partner- 



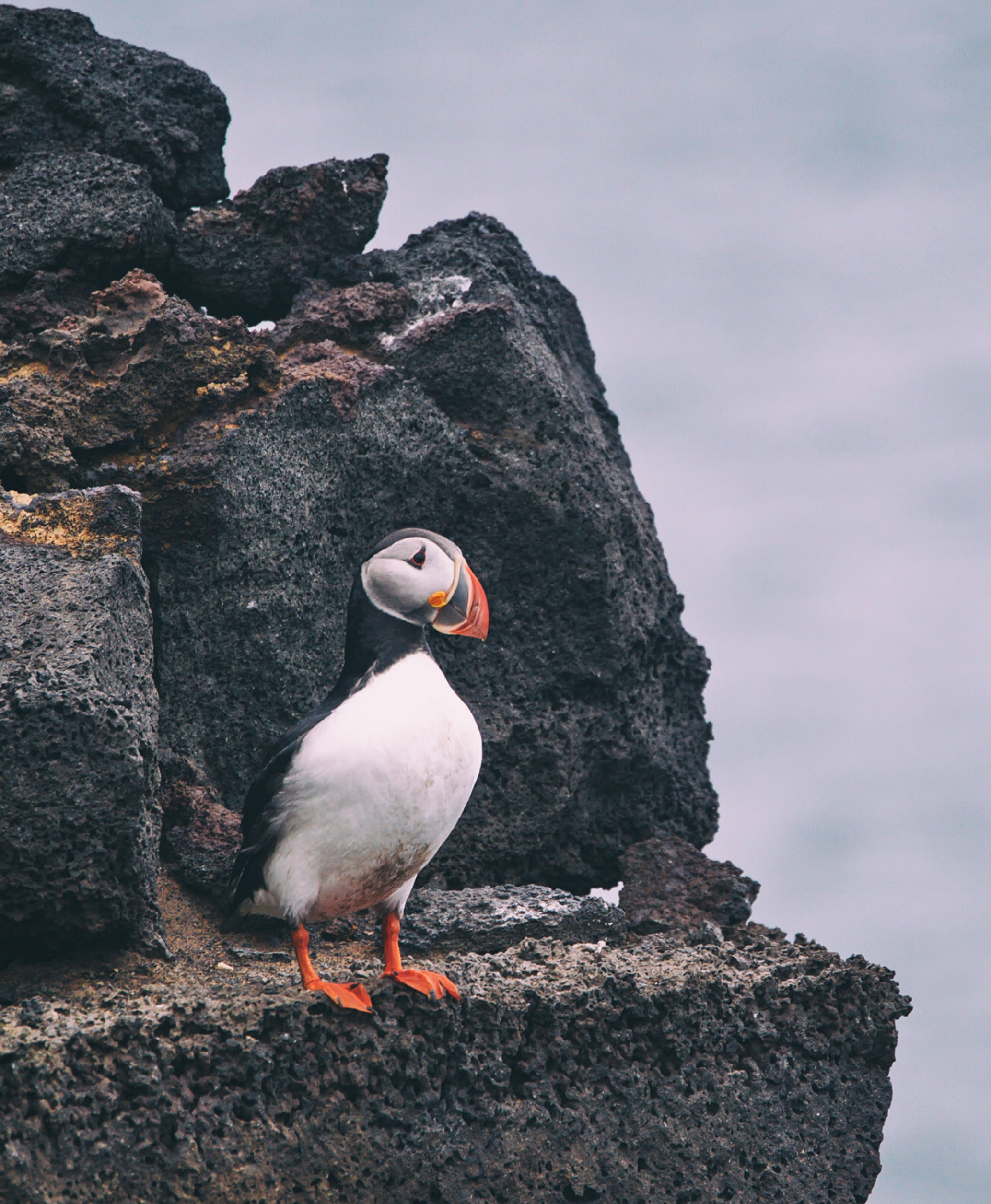


In 2016 the Nordic Co-operation Minister (MR-SAM) decided to increase efforts supporting economic development in the Arctic. It was acknowledged that there needs to be more knowledge on the types of actions the Nordic countries and the Nordic Co-operation within the auspices of the Nordic Council of Ministers (NCM) could take. This led to the making of the "Arctic Business Analysis".

The overarching aim of the Arctic Business Analysis is 1) to provide a better understanding of the Nordic Arctic business environment as part of promoting a greater focus on enablers and drivers of sustainable economic activities in the Nordic Arctic and 2) to generate practical recommendations on how the Nordic Co-operation can promote economic activities in the Nordic Arctic through the establishment of a data foundation upon which to draw fact-based conclusions. The findings of the analysis will feed into NCM's Arctic Co-operation Programme in which sustainable economic development is a key theme. Specifically, the analysis will contribute to NCM's focus on economic development and investments in the Arctic - a political priority for the Nordic Co-operation.

In addition to outlining enablers and best practices that can promote sustainable economic activities on behalf of the Arctic population, the analysis is also aimed at contributing to NCM's work with the United Nations Sustainable Development Goals (SDGs). Overall, the analysis will contribute to sustained, inclusive, and sustainable economic growth (SDG 8) in the Nordic Arctic, and an inclusive and sustainable industrialisation and promotion of innovation (SDG 9). Moreover, it will analyse sustainable economic activities related to bioeconomy, creative and cultural industries, and business co-operation, which would promote affordable and clean energy (SDG 7), sustainable cities and communities (SDG 11), and life below water and on land (SDG 14 \& 15) among others. 



\section{EXECUTIVE SUMMARY OF THE ARCTIC BUSINESS ANALYSIS}

All Nordic Arctic countries are paying more attention to the facilitation and strengthening of entrepreneurship and innovation. Denmark, Iceland, Sweden, Norway, and Finland perform very well, whilst limited data makes it difficult to assess Greenland and the Faroe Islands. Nonetheless, there are a number of potential developments which can help improve entrepreneurship and innovation environments across the Nordic Arctic regions. Firstly, entrepreneurial awareness and ability should be developed. This can be facilitated through an increased focus on integrating entrepreneurship education in national strategies, and also implementing such education through local initiatives and local operators. Secondly, collaboration between actors and regions in the Arctic should be ensured. Through such collaboration, the Arctic can improve its ability to diversify and fully utilise each other's entrepreneurial and innovative competitive advantages. Finally, the cultural bias that paints the region as an area with low economic and business development potential challenges Arctic development. This can adversely affect the region's ability to attract investments and capital. Overcoming this challenge through collaboration and branding the Arctic as a single market would therefore be a key driver for future entrepreneurial and economic growth in the region.

In the Nordic Arctic, Public Private Partnerships (PPPs) have not been used often as an infrastructure financing model. The region's limited experience with PPPs and the fact that standard PPP models in the market do not necessarily fit Arctic characteristics hamper the increased use of PPPs in the Nordic Arctic. Therefore, the public sector in

$\leftarrow \quad$ Snowboarder from Nuuk, Greenland. Photo: Mads Pihl / Visit Greenland the Nordic Arctic needs to collect data on PPP best practices and advice from PPP units in international organisations. Furthermore, there is potential to increase the competences of PPPs in the Nordic Arctic as a 
model to finance large-scale infrastructure projects. Initiatives should be taken to create an overview of Arctic infrastructure needs, experience, and supervise local governments and municipalities looking to engage in a PPP.

Business co-operation in the form of clusters in the Arctic are generally few, undeveloped, and still need to secure financing long-term, though local variations exists. Norway is a leading figure in supporting national cluster development through initiatives like Innovation Norway. Public support and increased cross-border co-operation are some of the drivers that will benefit cluster development in the Nordic Arctic. Public funding should ensure that business clusters can be created and developed while also ensuring a secure exit strategy so the clusters become financially sustainable. Furthermore, clusters can support their members and develop a greater market reach by co-operating across borders, as well as branding the region as a place for doing business.

Bioeconomy integrates a number of solutions for a sustainable future, both environmentally, socially, and economically. Bioeconomy is already an important economic segment in the Nordic Arctic, constituting $10 \%$ of the overall Nordic economy and moving towards $20 \%$ in some countries. Increasing the innovative use of biomass resources from land and sea presents a key opportunity to simultaneously ensure environmental sustainability and economic growth. Bioeconomy development should focus on increasing the value of products derived from biomass, and increasing the uses of side streams created by bioeconomy activities. These include practices such as the use of fish side streams for pharmaceutical products, wood residues in textile production or fish feed, etc. If bioeconomy in the Arctic is to be harvested, synergies between companies and industries must be built in both public and private sectors as well as across sectors and borders to facilitate the right public support and incentives to drive bioeconomy innovation, commercialisation and growth. Furthermore, the future bioeconomy requires substantial creative capabilities. Rebranding bioeconomy accordingly has the potential to attract a younger generation to an industry perceived as very traditional. As many bioeconomy activities are located in rural areas, developing bioeconomy also counters urbanisation, and promotes rural development and employment in the Nordic Arctic.

The Nordic Arctic creative and cultural industries of film, tourism, and indigenous cultural businesses are becoming increasingly important platforms through which the Nordic Arctic countries can create value and growth - economically, socially, and culturally. Despite significant variations in size and development, Nordic Arctic film industries are gaining considerable traction across the entire Nordic Arctic region. Policy support such as public funding and production rebates have been instrumental to the success of film industries, but ensuring long-term development requires knowledge sharing and collaboration 


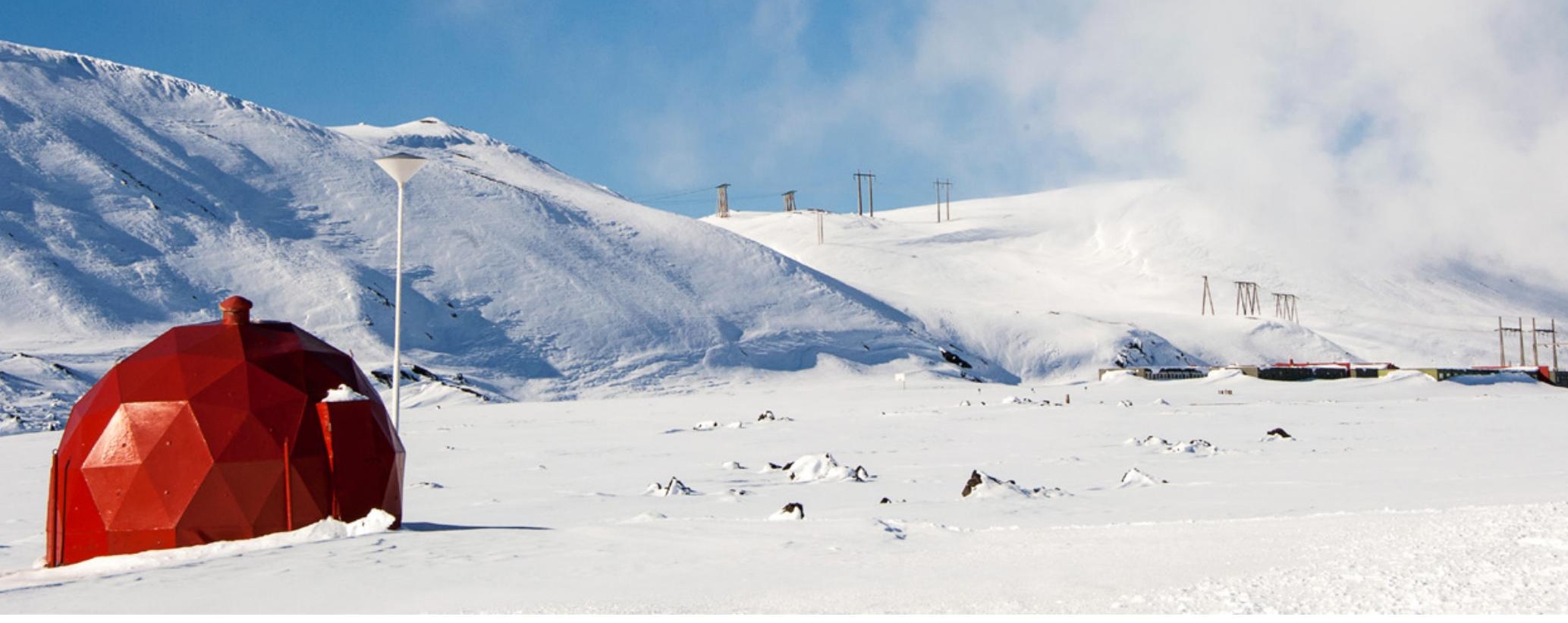

$\uparrow \quad$ Red dome structure, part of the Krafla geothermal power plant near Myvatn in Iceland, Krafla is Iceland's largest power station and also it's second oldest.

Photo: Scanpix in developing film production skills e.g. through official training across the Nordic Arctic. Nordic Arctic tourism has grown steadily in the last decade. Public support, public-private collaborations, and transnational collaborations have been key in developing Arctic tourism. Transnational collaboration shows great potential, as Arctic regions, especially those in Finland, Norway, and Sweden, are generally perceived as one destination by the tourism market. Growth in Sami and Inuit indigenous businesses offer an opportunity for economic growth whilst integrating Arctic indigenous peoples into the regional and international economy. Business opportunities include indigenous tourism, film, and other cultural activities. However, it is important to ensure that Nordic Arctic Indigenous peoples' culture, life, and creative work are promoted and not misrepresented when developing these areas. 


\section{THE NORDIC \\ ARCTIC BUSINESS \\ ENVIRONMENT: \\ ENTREPRENEURSHIP \\ AND INNOVATION}

This section presents a mapping of key entrepreneurship and innovation policies and economic activities in the Nordic Arctic, focusing on non-sector specific initiatives to give an overview of policy trends in the region. Entrepreneurship occurs when "actions take place on the basis of opportunities and good ideas, and are translated into economic, social and/or cultural value for others." ${ }^{2}$ Along similar lines, innovation is the process of promoting changes in technologies, products, or administrative practices. It is important, however, that development of entrepreneurship is embedded in the local social and cultural contexts, so as not to force a foreign interpretation of entrepreneurship in a context where there is no match. This section identifies drivers and enablers to

$\leftarrow$ Modern green tram in Helsinki. Photo: Scanpix develop entrepreneurship and innovation and presents opportunities for action through specific examples.
SUMMARY: The Nordic Arctic has increased its attention toward entrepreneurship and innovation, attempting to realise the potential for economic growth and development of jobs. Iceland, Sweden, Norway, and Finland perform especially well, whilst limited economic data make it difficult to assess Greenland and the Faroe Islands. However, research indicates that their performance is significantly lower than that of Iceland, Sweden, Norway, and Finland. All states and countries have established organisations that facilitate entrepreneurship and innovation through basic services such as financing and ad- visory services, with some organisations offering a broad variety of specialised services. Only Sweden, Norway, and Finland have implemented entrepreneurship education strategies, while entrepreneurship education activities in Iceland, Faroe Islands, and Greenland are limited to selected local initiatives. The main drivers for further development of entrepreneurship and innovation are the development of an entrepreneurial mindset, collaboration between actors and regions, and overcoming a general cultural bias against the Arctic region. 


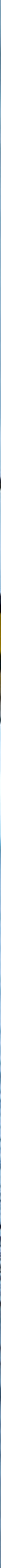




\subsection{MAPPING OF ECONOMIC ACTIVITIES AND POLICIES}

The Nordic Arctic business environment is characterised by an increased focus on entrepreneurship and innovation, which are perceived as a way to develop solutions to local and global challenges, and thereby increase the country's competitiveness in a globalised economy. Although the concepts of entrepreneurship and innovation are characterised by some general dimensions, it is important to highlight and acknowledge that the understanding of entrepreneurship and innovation is grounded in regional, national, and cultural contexts by which incentives and activities may vary.

Overall, Nordic Arctic policy makers have focused on high-growth companies, SMEs, and start-ups since these are perceived to drive job creation, productivity growth, and foster innovation. All Nordic Arctic countries have established organisations that facilitate entrepreneurship and innovation through basic services such as financing and advisory services with some organisations offering a broad variety of specialised services. ${ }^{3}$ Nevertheless, only Sweden, Norway, and Finland have formulated and implemented specific strategies for entrepreneurship education. ${ }^{4}$ Iceland does not have any strategy or policy initiatives at the government level. Therefore, most initiatives are at the grassroots level. ${ }^{5}$ The Faroe Islands have initiated a process to develop entrepreneurship education at the primary school level, while Greenland is currently implementing its first formalised activity related to entrepreneurship education. ${ }^{6}$ Business angels and venture capital funds also play a substantive role in defining the set of opportunities in the Nordic Arctic regions. For example, the Nordic Venture Network represents 11 of the largest technology venture capital funds. The Nordic Business Angel Network brings together active business angels in the Nordics and connects them with start-ups in the region seeking growth and investment opportunities. However, these opportunities are not further discussed in this report.

Although it is difficult to get an accurate picture of the level of economic activity relating to entrepreneurship and innovation, the Nordic states (Sweden, Finland, Iceland and Norway) are generally considered as high performers. Throughout Sweden, Norway, and Finland, employ- 


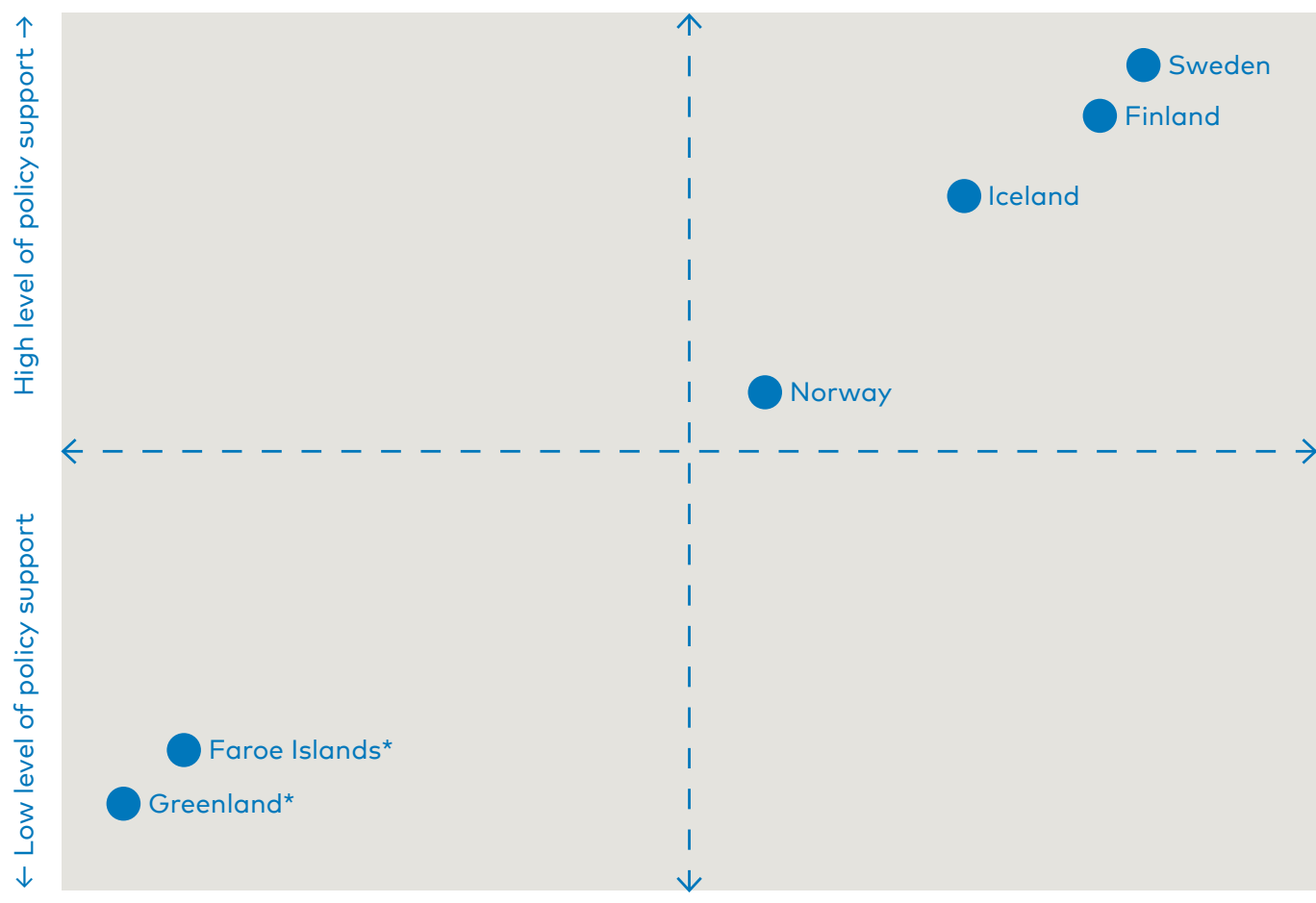

$\leftarrow$ Low level of economic activity

High level of economic activity $\rightarrow$

er enterprise birth rate is around $10 \%$. Furthermore, enterprises with innovation as a core activity ${ }^{7}$ represent more than half of enterprises throughout the Nordic States, with 54.2\% in Sweden, 57.6\% in Norway, $55.3 \%$ in Finland, and $59.2 \%$ in Iceland.

Although not always directly related to activities concerning entrepreneurship and innovation, indirect measures and outcomes of these parameters involve employment, the number, size and value-add of businesses, R\&D expenditure, and patent applications. Micro, Small, and Medium Sized Enterprises (MSMEs) ${ }^{8}$ in Sweden, Finland, Norway, and Iceland make up the vast majority of companies (over $99 \%$ ), employ around $2 / 3$ of all employed, and are responsible for around $2 / 3$ of total economic value added. In all four countries, most MSMEs are characterised as micro enterprises, defined as having less than 10 employees. The highest rate of micro enterprises is found in Sweden, where 94.6\% of all companies are micro enterprises. The lowest rate is found in Norway, where micro enterprises make up $91.8 \%$ of all companies. Micro

$\uparrow \quad$ *Note that available economic data is very limited for Greenland and Faroe Islands.

Note: Based on a qualitative assessment of data on the level of support and economic activity for each country

$\rightarrow \quad$ Molde, Norway. Photo: Dong Zhang 

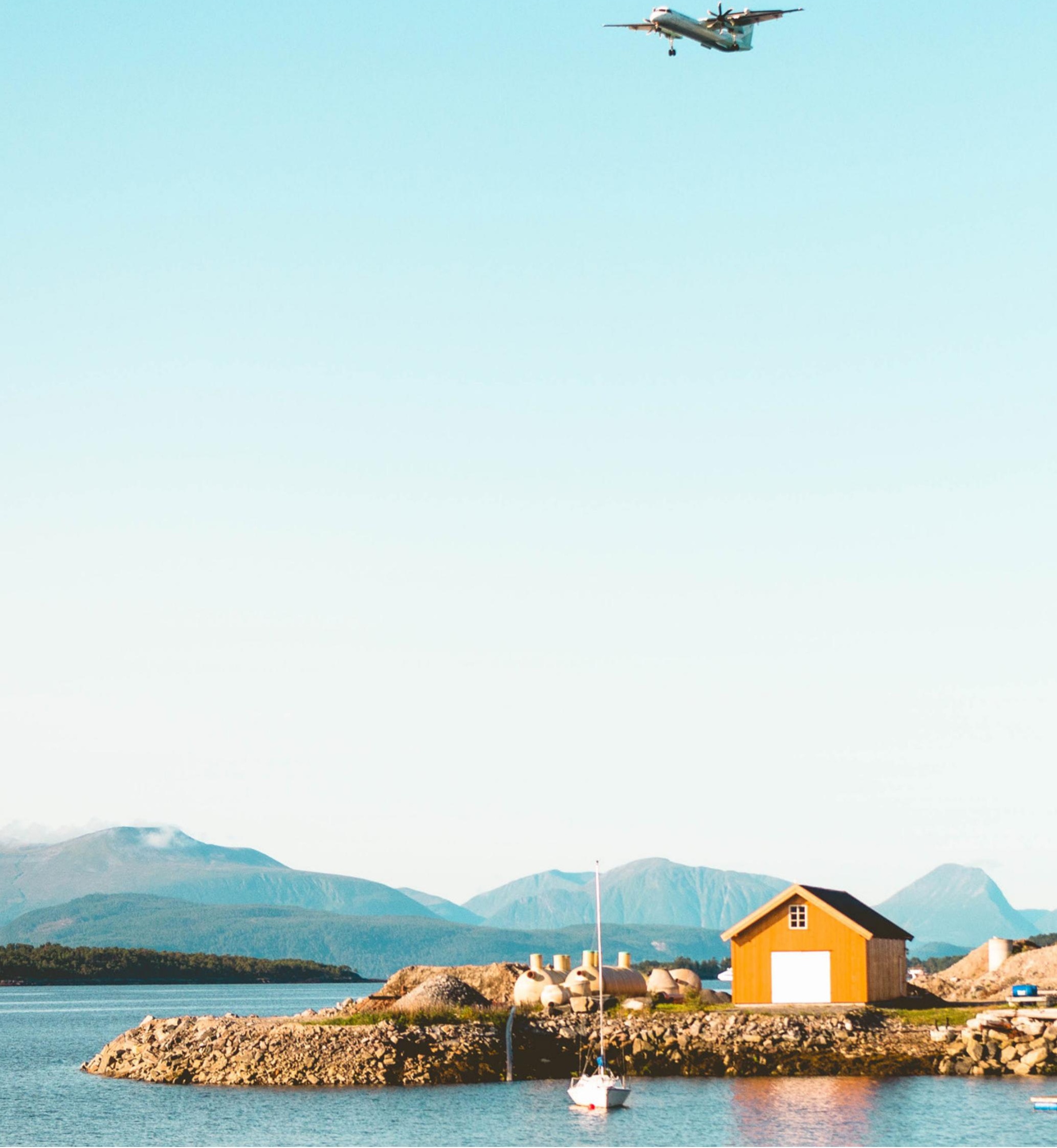

21

The Nordic Arctic Business Environment:

Entrepreneurship and Innovation 

$\downarrow \quad$ Sources: Data and

calculations based on data from EUROSTAT, OECD and

The World Bank

a 2014 data

b 2015 data low-patent intensity is found. The area, consisting of Norway (Finnmark, Troms, Nordland), Sweden (Norrbotten and Västerbotten), and Finland (Lapland, Northern Ostrobothnia and Kainuu), has a rate of around 0.14 patent applications to the national office per 1,000 capita, while Norway, Sweden, and Finland as a whole have a rate of around 0.22 (2003-2015 average). ${ }^{10}$ Within the northern regions, Northern Ostrobothnia has the highest average number of national patent application of 81.2 per year, followed by Västerbotten with 47.5, Norrbotten with 37.4. Meanwhile the other regions have a much lower patent activity, ranging from 5.5 to 20 on average per year. For the same period, residents of Iceland on averaged filed 50.6 applications to the national office.

Specific data on economic activity for entrepreneurship and innovation in the Faroe Islands and Greenland is very limited, and available economic data relates mostly to macroeconomic trends, production, and trade among other such themes. In 2012, the Faroe Islands had 2,339 companies, which is around 1 company per 21 people, while Greenland in 2015 had 4,055 companies, making up around 1 company per 14 people. The Nordic countries show similar rates, from Iceland with 13 people per company to Finland with 24 people per company. However, this statistic does not necessarily measure entrepreneurial performance, as this varies from region to region. ${ }^{11}$

\begin{tabular}{|c|c|c|c|c|c|c|}
\hline & SWE & NOR & FIN & ISL & FRO & GRL \\
\hline $\begin{array}{l}\text { Global Entrepreneurship Index } \\
2017 \text { Ranking }\end{array}$ & 4 & 22 & 11 & 6 & NA & NA \\
\hline $\begin{array}{l}\text { Global Innovation Index } 2017 \\
\text { Ranking }\end{array}$ & 2 & 19 & 8 & 13 & NA & NA \\
\hline Employer Entreprise Birth Rate (\%) & $10.3 \%$ a & $9.00 \% \%^{a}$ & $11.2 \%{ }^{a}$ & NA & NA & NA \\
\hline $\begin{array}{l}\text { Enterprise Entries } \\
\text { (\%: } 2016 \text { Q1 vs. } 2007 \text { Q1) }\end{array}$ & $22.2 \%$ & $13.2 \%$ & $-19.6 \%$ & $-18.3 \%$ & NA & NA \\
\hline $\begin{array}{l}\text { Enterprises with Innovation as } \\
\text { Core Activities }\end{array}$ & $54.2 \%{ }^{a}$ & $57.6 \%$ & $55.3 \%{ }^{a}$ & $59.2 \%{ }^{a}$ & NA & NA \\
\hline R\&D Expenditures as \% og GDP & $3.26 \%$ & $1.93 \% \%^{b}$ & $2.9 \%{ }^{b}$ & $2.19 \%{ }^{b}$ & NA & NA \\
\hline $\begin{array}{l}\text { Patent applications by residents as } \\
\% \text { of population }\end{array}$ & $0.021 \%{ }^{b}$ & $0.022 \%^{\mathrm{b}}$ & $0.024 \%{ }^{b}$ & $0.012 \%{ }^{\mathrm{b}}$ & NA & NA \\
\hline
\end{tabular}


29.

Thes H.7.

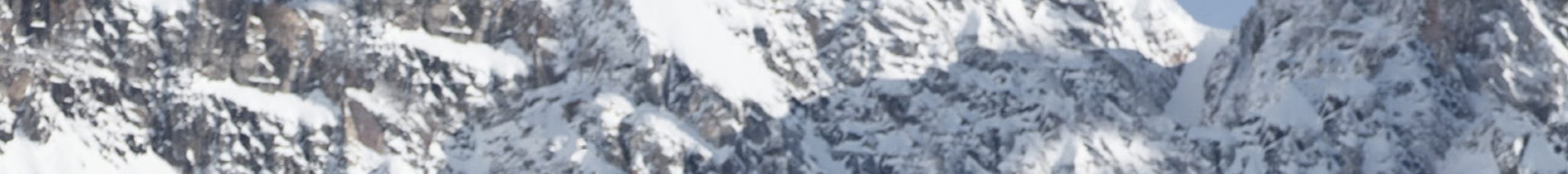

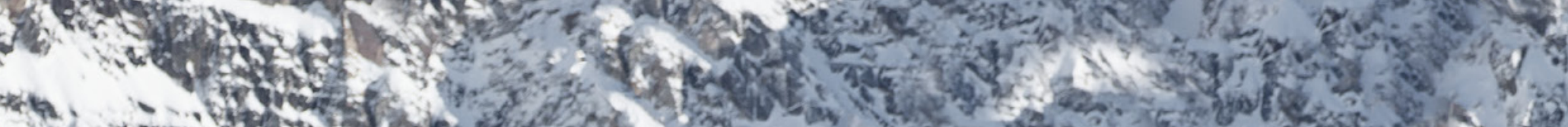

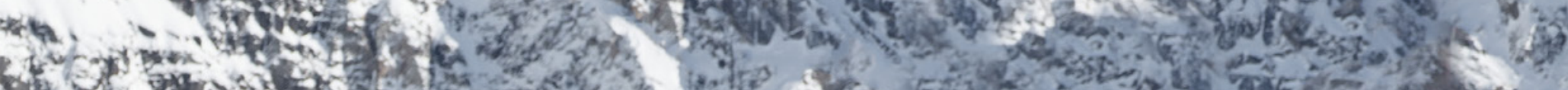

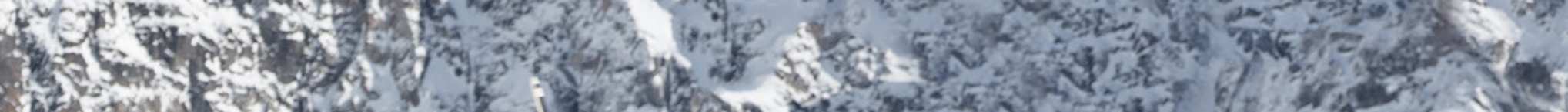
H.

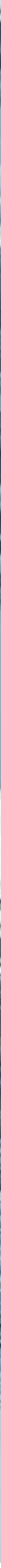




\subsection{DRIVERS AND ENABLERS OF BUSINESS DEVELOPMENT}

The creation of businesses and innovative products and processes is key to improving the livelihoods and lives of people in the Arctic region. SME's contribute to a large share of employment and add a lot of value to the economy. The general challenges of entrepreneurship and innovation relate to general business challenges of the Arctic. These include such characteristics as a small and scattered market, lack of investment, and a lack of human capital. On the other hand, the Arctic region does offer many opportunities. There are several competitive gaps that need to be filled in certain industries and areas, Arctic specific resources, and a unique Arctic cultural heritage, including indigenous and traditional knowledge. To enable and drive Arctic entrepreneurship and innovation with the goal of creating sustainable business development, three key drivers have been identified.

First is the development of entrepreneurial abilities embedded in local cultural and economic contexts. All of the Arctic countries have established basic support systems for entrepreneurs, but some regions experience limited demand because people lack entrepreneurial abilities and therefore do not intend to engage in entrepreneurial activities. Generally, entrepreneurial capabilities relate to the ability to turn ideas into action in the local cultural context, while being able to see opportunities, take calculated risks, and accept change as well as uncertainty. A way to facilitate the development of entrepreneurial abilities is through an increased focus on entrepreneurship education in which entrepreneurial competences, interpreted in the cultural context, are integrated in school curriculum and classes. Entrepreneurship education teaches children and young people how to engage in entrepreneurial activities and how to translate an idea into the development of a product or service. Entrepreneurship education in schools and educational institutions also has the potential to increase the awareness of entrepreneurship as a career choice, and promote the skills and knowledge needed to develop stronger entrepreneurial cultures in the Nordic Arc- 
tic. ${ }^{12}$ Individual entrepreneurship educational activities can be implemented at local levels, but to build a successful holistic system, efforts on several levels need to be implemented through collaboration with key actors from all aspects of the society. Furthermore, fundamental enablers are a common understanding of entrepreneurship, a strategy for entrepreneurship education, and actors able to implement activities and ensure continued focus on entrepreneurship education. ${ }^{13}$ All this embedded in the local context and understanding of entrepreneurship, knowing that "regionality" shapes institutions in which entrepreneurship education is administered and is therefore substantive in influencing educational objectives, outcomes resources and cultures. ${ }^{14}$

Examples of entrepreneurship education enablers in the Arctic countries and states are the establishment of the Foundation of Entrepreneurship in Greenland (see case study), Flashes of Genius (Snilleblixtarna) in Sweden, and Young Achievement's Job Shadow project in Finland. Flashes of Genius focus on training teachers to raise children's interest in entrepreneurship and is implemented through local and regional partners across Sweden. The advantage of Flashes of Genius is a cost-effective model in which

"A way to facilitate development of entrepreneurial skills is through an increased focus on entrepreneurship education in which entrepreneurial competences will be integrated in school curriculum and classes and thus interpreted in the cultural context." the respective municipalities fund partners and minimises the need for employees. A further driver of success is the inclusion of local companies that help direct the development of entrepreneurial and technical skills toward those needed by companies. ${ }^{15}$

In Finland, the Job Shadow project illustrates that entrepreneurship education can increase the entrepreneurial mindset of young people. Implemented by Junior Achievement (JA), the largest provider of entrepreneurship education in Europe, the Job Shadow project offers students the opportunity to follow a company leader for a day to gain insights into working in a company, leadership, decision-making, HR etc.. $67 \%$ of project participants from 2000-2013 (18-30 years) indicated that participating in the project made them consider setting up their own company, and $11 \%$ had already established a company influenced by the project. ${ }^{16}$ The drivers of JA's success are the combination of experimental learning outside and inside the classroom, as well as the integration of schools in the local business environment.

Second is to ensure collaboration between actors and regions in the Arctic. The Nordic countries have increasingly focused on narrowing the gap between public policy and businesses to exploit innovative business opportunities in the Arctic. Collaboration in the Arctic is particularly vital, as the Arctic environment is characterised by low population density, low local economic diversity, and is often perceived as a region with 
$\downarrow \quad$ Brewery in Nuuk in Greenland.

Photo: Visit Greenland low economic attractiveness by "southern" and international stakeholders. By collaborating across actors and regions, the Arctic can improve its ability to diversify and exploit each other's entrepreneurial and innovative competitive advantages. The collaboration can also extend to the global scale where Arctic value chains can be linked to global value chains to further promote innovation. Each Nordic Arctic city or region has certain advantages pertaining to natural resources, human capital etc., but they are not able to diversify within a single city or region in the same way as metropolitan areas because of sparse populations and often low variety of skills. Collaboration between actors, cities and across boarders open opportunities for improved business developments. An example of collaboration could be the potential to combine Swedish expertise in marketing and sales with Finnish engineering expertise to enable the Finnish companies to grow and expand internationally. An

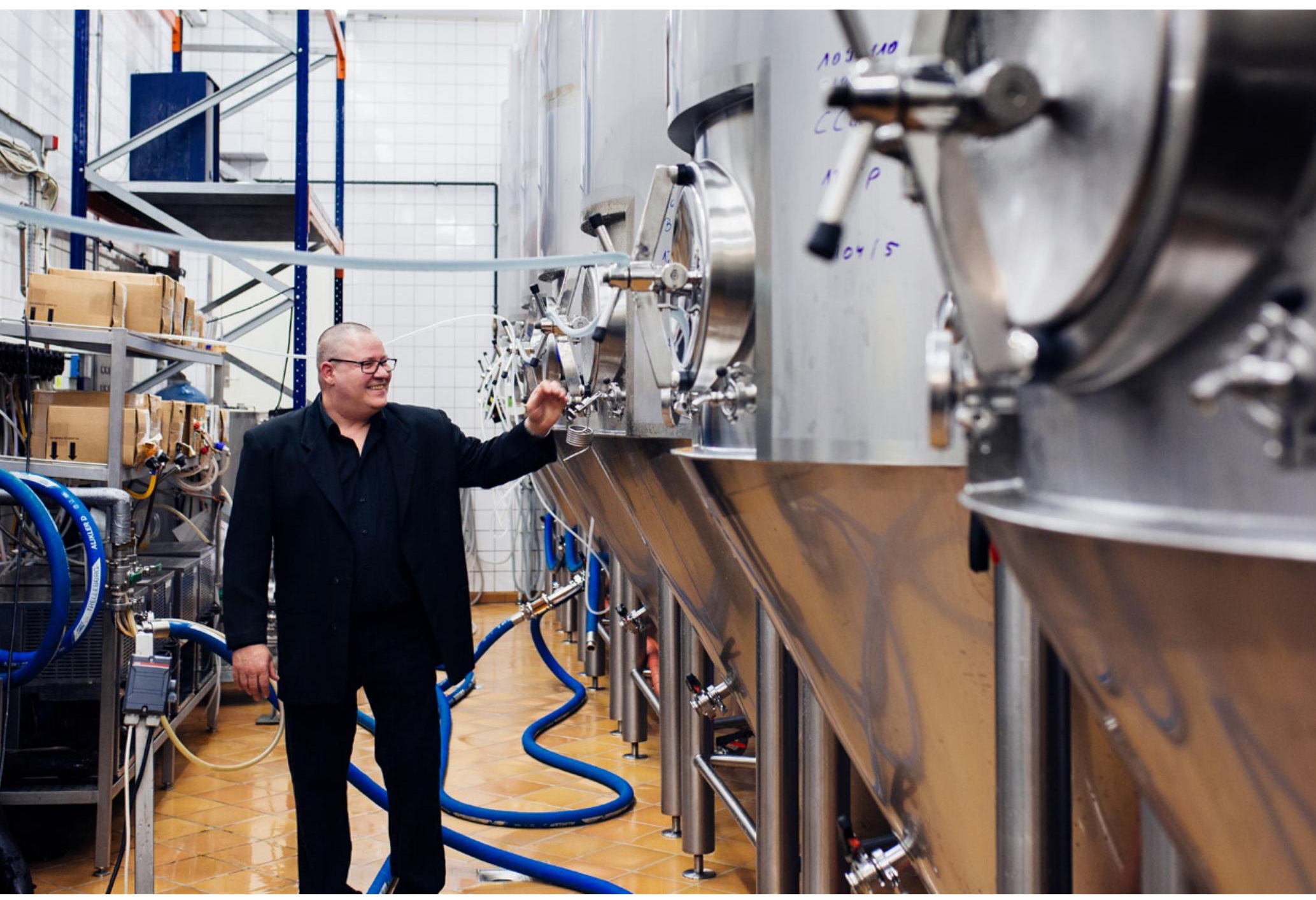


example of a specific project is the recent collaboration between Oulu, Luleå, and Tromsø with the aim of establishing an Arctic Innovation Hub. The project would seek to exploit Oulu's model for collaboration and talent management, Luleå's understanding of the commercialisation process, and Tromsø's understanding and vision of Arctic opportunities and challenges (see case study for more details on the framework model for collaboration). ${ }^{17}$ Such Innovation hubs have the potential to increase the possibilities for new, multidisciplinary innovations by merging eco-systems with complimentary competitive advantages.

Moreover, collaboration between Arctic regions carries great potential to attract attention from the Nordic Arctic's southern regions and the international environment. By increasing the size of the markets and the number of business opportunities, the Arctic regions can raise the attractiveness of the Arctic area as a whole. This can be done through cross-border collaboration like the collaboration between Oulu, Lulea, and Tromsø, in which the vision is to establish an Arctic Valley where it is possible to gain access to the whole Arctic area in Finland, Sweden, and Norway through any region or node of the hub. Another meth-

"Collaboration between Arctic regions carries great business potential to attract attention from the centres and capitals of the Nordic Arctic and the international environment. A positive branding of the Nordic Arctic in terms of business potential and investments should be a focus in the future." od would be to establish an Arctic regional representative hub in one country. In Northern Sweden, the city of Lulea plays a leading role in branding the northern region of Norrbotten as a whole instead of only branding the city. The rationale is that international investors do not look for cities to invest in but larger regions. As such attracting investors to the Arctic region as a place with diverse investment opportunities, will enable cities and local regions to access capital and international markets - using the Arctic region as a stepping stone for business development.

Finally, a key driver is overcoming the cultural bias against the Arctic region. Many private investors have little experience and interest in the Arctic region. This is partly related to the perception of the region as an area with low economic growth and limited potential for business development. Also, the region is very distant from the Nordic's central business hubs in the south, where investors are used to "having everything in their backyard." The implication is that many Arctic companies struggle to find growth capital to expand nationally and internationally. To overcome this, the Arctic Business Incubator in Sweden has initiated several trips to the south to engage with investors and invite them for company visits in the north. The outcome is to change perceptions and create awareness about the Arctic region as a place with many good investment opportunities.

$\rightarrow \quad$ Photo: NordForsk 


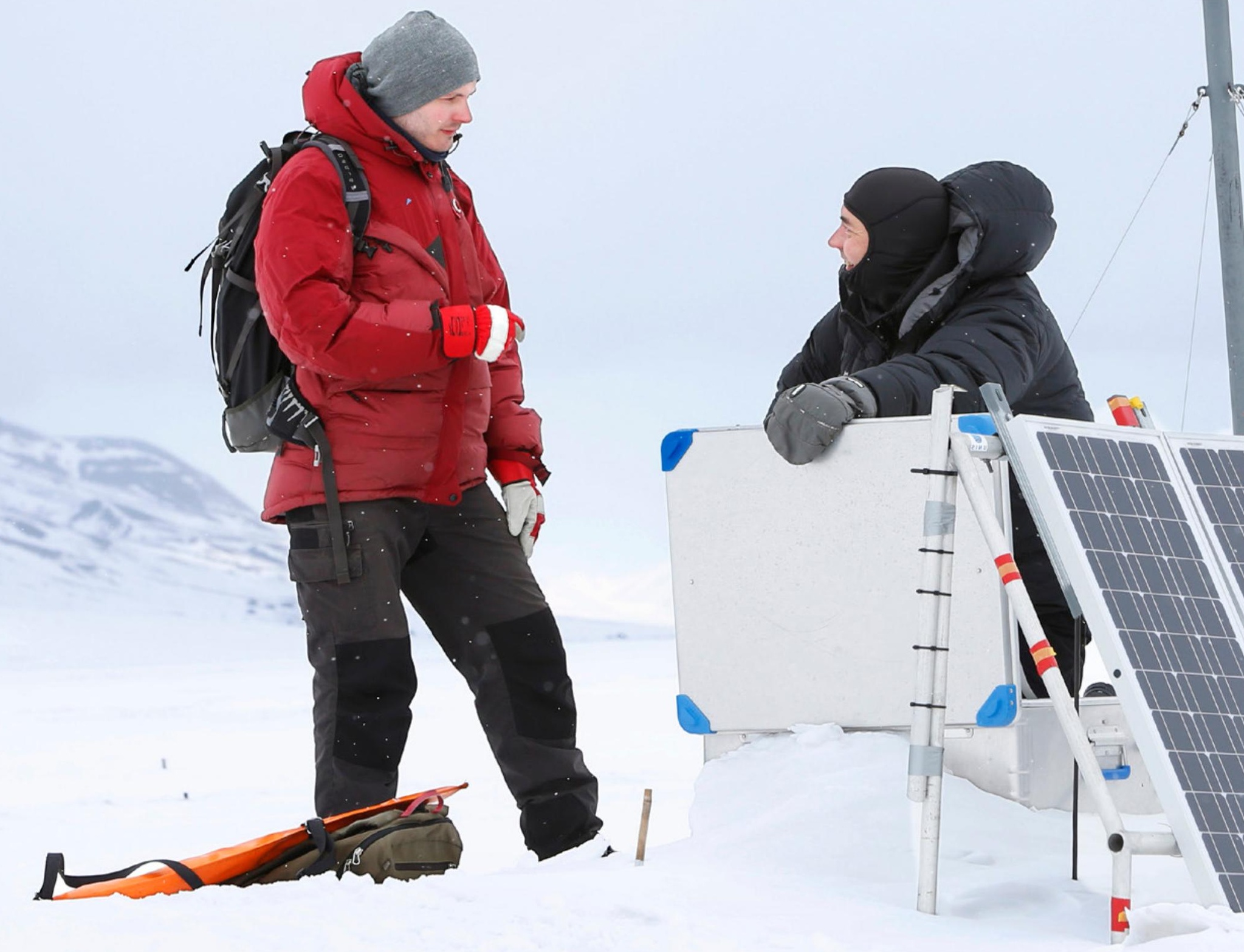




\section{DEVELOPING ENTREPRENEURSHIP EDUCATION IN GREENLAND}

Organisation: Foundation for

Entrepreneurship Greenland

Sector: Entrepreneurship Education

Region: Greenland

\author{
Contact: Christian Vintergaard \\ CEO \\ Mail: Christian@ffe-ye.dk
}

\section{Illustrates ways to promote entrepreneurial education and develop an entrepreneurial culture that can increase school attendance, the educational level, as well as the number of entrepreneurs.}

Greenland is generally challenged by low education levels, emigration and a lack of employment opportunities. In the education sector, Greenland experiences specific problems with the quality of education as well as low interest in attending school among some children.

To combat these challenges, the Greenlandic Government has initiated a partnership with The Danish Foundation for Entrepreneurship to promote entrepreneurship education through the establishment of the Foundation for Entrepreneurship Greenland (FFE Greenland) - a subsidiary of the Danish Foundation. The aim of the organisation is to spread and increase the quality of entrepreneurship education, to teach children and students to think innovatively and turn ideas into actions, all while increasing the spirit of entrepreneurship. Moreover, studies show that entrepreneurship education facilitates a willingness to learn, which indicates that in relation to the Greenlandic environment, the main benefit may be an increase in the interest to learn and attend school. In the long term, this could improve education levels and the number of skilled employees in Greenland.

FFE Greenland is currently establishing its organisation and has initially been allocated EUR 175,000 in the Greenlandic Finance Act 2017. This has already been supplemented with donations from private donors. The organisation has started educating teachers to gain competences in working with innovation and entrepreneurship as part of general education. The target group is Greenlandic teachers and educators, but for the first course, several other professions, for example civil servants, also applied (and were admitted) because they believed they could benefit from the course.

FEE Greenland also plans to implement entrepreneurial events and competitions for students to generate awareness about entrepreneurship education and support selected 


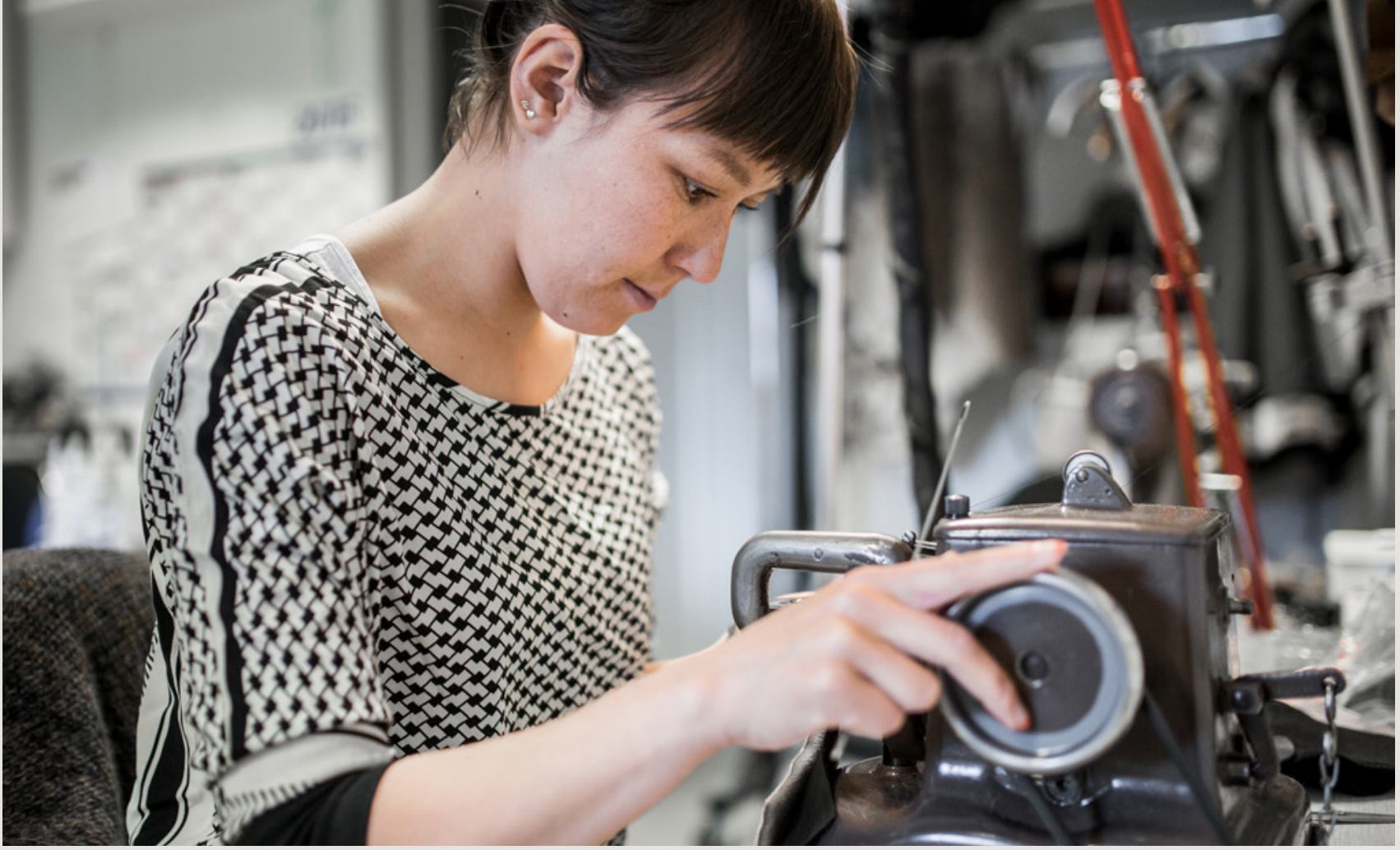

$\uparrow \quad$ One of the seamstresses at Qiviut in Sisimiut in Greenland. Photo: Mads Pihl / Visit Greenland

students with micro grants to develop innovative start-ups. FEE has good experience with competitions. But based on a previous pilot study, they do not initially expect a great demand for the grant because students tend not to engage in entrepreneurial activities. "There needs to be an entrepreneurial culture before entrepreneurs are developed," CEO of FEE Christian Vintergaard.

\section{Success Factors}

As FEE Greenland is a very new initiative, it has yet to prove itself. However, FEE builds their success on understanding the combination between business and education, and specifically understanding teachers' mindsets and conditions e.g. time constraints. Therefore, they focus on developing ready-to-use programmes and materials that make it easy for teachers to include entrepreneurship edu- cation in their classes. The long-term goal is more Greenlandic start-ups and more entrepreneurial employees.

\section{Drivers and Challenges}

A major challenge for entrepreneurship and innovation is an absence of entrepreneurial ability and a lack of data and information. These hinder a fact-based identification of specific problems and challenges. A key driver of entrepreneurship education is the development of a national strategy, a dedicated budget, and an operator to implement activities and monitor development. This ensures that entrepreneurship education is prioritised, while also facilitating a trickledown effect to educational institutions. 


\section{PROMOTING BUSINESS GROWTH IN NORTHERN SWEDEN}

\author{
Organisation: Arctic Business Incubator \\ Sector: Not sector specific \\ Region: Northern Sweden
}

Contact: Jens Lundström

VD

Mail: jens.lundstrom@abi.se

\section{How an Arctic incubator deals with the challenges of the Arctic business environment and challenges the cultural bias in favour of the south.}

The Arctic Business Incubator ( $\mathrm{ABI}$ ) is a regional incubator focusing on the northernmost part of Sweden with offices in Luleå, Skellefteå, Piteå, and Kiruna. It was established in 2005 by the University of Luleå University of Technology, but now receives funding from various private and public organisations. $A B I$ is part of Vinnova's Excellence programme with funding of EUR 1.7 million for a four-year period (2016-2019).

$A B I$ 's aim is to develop innovative ideas into businesses that can create and maintain profitable and viable international growth. They are experts in delivering a range of services (management support, team and recruitment, office space and labs, and access to funding etc.) to the whole region and for many different sectors such as forestry, mining, space, clean tech and energy, ICT, and creative industries. ABI's clients range from university researchers and students to private entrepreneurs and established companies or research institutes. Key to the organisation is the focus on exports and international aspiration as criteria for business development.

\section{Success Factors}

Key to the success of $A B I$ and its companies their push for early commercialisation as opposed to continued product development. In this way, entrepreneurs meet customers early on and get a better understanding of demand and market requirements. Furthermore, ABI works across municipalities and sectors, and has created a successful platform for collaboration. $A B I$ is the official Swedish national space incubator (for European Space Agency and Swedish National Space Board) and ensures a collaborative and inclusive process with other organisations and cities to the benefit of all stakeholders. 


\section{A FRAMEWORK FOR COLLABORATION TO FACILITATE INNOVATION AND BUSINESS DEVELOPMENT}

\author{
Organisation: Oulu Innovation Alliance \\ Sector: Not sector specific \\ Region: Finland
}

\author{
Contact: Sami Niemelä \\ Head of Agile commercialization, OIA \\ Mail: Sami.M.Niemela@oamk.fi
}

\section{A unique framework model for coordination around innovation and entrepreneurship driven by an inclusive design process, a joint vision, and trust.}

\begin{abstract}
After the collapse of the Finnish mobile phone company Nokia in 2009-2014, the city of Oulu experienced increases in unemployment and a need for business development. To enable business development, key actors in the city decided to collaborate and combine resources and established Oulu Innovation Alliance (OIA). OIA is a strategic agreement between education and research institutions, companies, and the public sector. It was created in 2009, but in 2016 a new agreement was made and five ecosystems (Northern City with Attractive Opportunities, Agile Commercialization, ICT and Digitalization, Industry 2026, and OuluHealth) were developed to provide a framework for collaboration between key actors. With the new agreement, the OIA shifted focus from research funding towards a business approach aimed at facilitating SME growth and new business opportunities.
\end{abstract}

\section{Success factors}

As the OIA is still young, it is difficult to assess its success. Nevertheless, it is important to point out the uniqueness of its structure, which could act as a model for structuring collaboration and activities related to entrepreneurship, innovation, and business development. OIA has not established a separate organisation or introduced new services, except coordination. Instead the individual partners have committed in-house resources to drive the work forward. The practical execution of OIA's work thereby depends on the partners, and its intention is to bring coordination and collaborative efforts to develop activities in pre-existing organisations. 


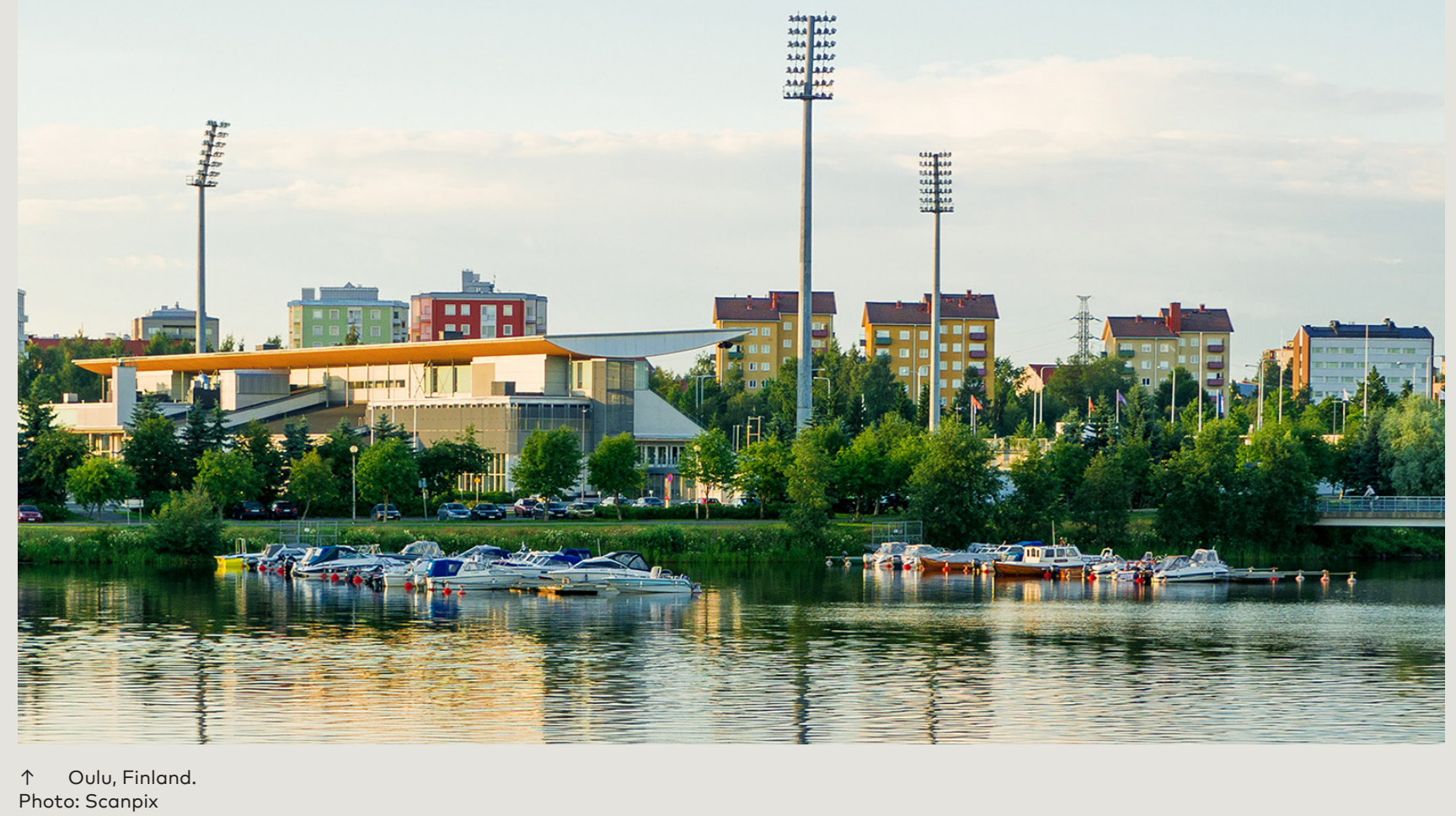

\section{Drivers and challenges}

OIA's unique collaboration framework was driven by three factors. First was the process leading to an agreement during which the partners took time to understand each other's needs, the big picture, and the potential roles of each partner. This took place through a design process involving workshops, negotiations, benchmarks, and background analyses. Second was the establishment of a joint vision for OIA that outlined its activities and operations to guide future collaboration and coordination in the ecosystems. To practically facilitate the implementation, PowerPoint templates and common statements were developed for all partners to use in communications. Third was the development of trust between partners and participants, as the OIA structure relies on partners to drive coordination and execute activities. Key challenges that OIA is addressing are the lack of big-pic- ture thinking and working in silos, which has been characteristic of the organisations in the past. This is an ongoing process.

In addition to the collaboration in Oulu, the OIA also sees a major opportunity for developing a similar collaboration structure across borders, for example, with cities like Tromsø in Norway and Luleå in Sweden. The three cities have different strengths and by collaborating, they will be able to leverage each other's strength to the benefit of business developments in all cities. For example, Oulu's strength in technological innovation in combination with Luleå's international commercialisation and growth competences have the potential to enable SMEs to grow beyond the local market. Together the three cities also make up a larger market. When structured and branded in the right way, together they can attract international investors who would not have been interested in the cities individvally. 


\section{IMPROVING SUSTAINABILITY \\ THROUGH HEAT RECOVERY AND ALGAE PRODUCTION}

\author{
Organisation: Finnfjord \\ Sector: Ferrosilicon Producer \\ Region: Norway
}

\author{
Contact: Geir-Henning Wintervoll \\ Mail: Geirw@finnfjord.no
}

\section{How a ferrosilicon producer improves its sustainability through innovative initiatives driven by clear goals, a willingness to take risks, public support, and a strong focus on human capital}

Finnfjord was founded in 1983. It is located in the northern part of Norway and has 130 employees. Today it is one of the world's most energy-efficient and environmentally-friendly producers of ferrosilicon. It has a production capacity of around 100,000 tons of ferrosilicon, 20.000 tons of silica, and $340 \mathrm{GWh}$ of electricity from its energy recovery plant.

\section{Success factors}

Since the beginning, Finnfjord has continually increased its efficiency, allowing it to increase production while keeping a stable number of employees. It has managed to commercialise silica dust, which originally was a waste product from the ferrosilicon production, and it has significantly lowered its electricity consumption by investing in a heat recovery system - potentially saving up to $40 \%$ of its energy consumption, equivalent to the electrical consumption of 21,192 Norwegian households.

Furthermore, since 2015 Finnfjord and the Arctic University of Norway (UiT) have worked on reducing $\mathrm{CO} 2$ emission through the production of algae that "eat" Finnfjord's CO2 emission. The algae are then be sold as fish feed. Currently, Finnfjord has set up three tanks full of algae and is entering stage 4 out of 5 on rendering it economically viable. When they reach stage 5 , each tank will contain around 3 million litres of algae and can reduce Finnfjord's $\mathrm{CO} 2$ emission by $1.9 \%$ i.e. 26 tanks have the potential to reduce emission by around $50 \%$.

\section{Drivers and challenges}

The key drivers of Finnfjord's innovative initiatives have been setting a clear goal, willingness to take risks, public grants, and hu- 


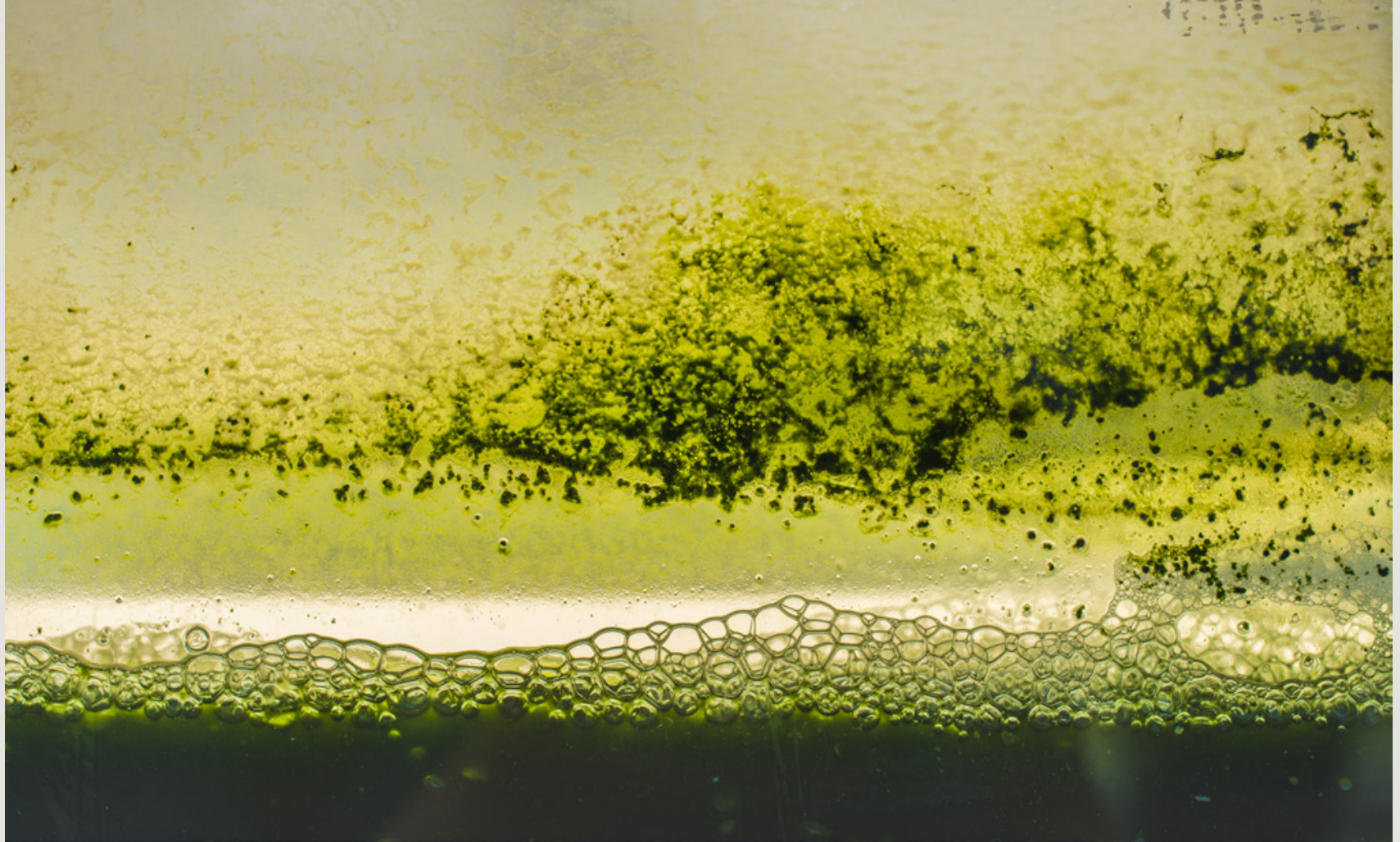

$\uparrow \quad$ Algae production. Photo: Scanpix

man capital. Setting a goal and developing a high-level plan to achieve it is vital because it guides the company in the same direction, and ensures commitment and resources to fulfil the goal. Finnfjord's goal is to cut costs through innovative initiatives to be able to compete with large Chinese producers, while also significantly reducing their own $\mathrm{CO} 2$ emission footprint. Furthermore, willingness and acceptance of risk is central when dealing with research and innovation, as a specific outcome is not guaranteed. However, to minimise risk and increase the economic viability of projects, Finnfjord has been dependent on public grants. Grants have the ability to drive new innovations by sharing part of the economic risks. However, the grant system sometimes indirectly challenges the incentive from becoming a front-runner in new research areas, as grants to similar projects can be dramatically increased after certain projects have proven valuable. This may discourage compa- nies to take the lead in new research areas, as followers can potentially receive greater economic support by waiting.

Additionally, a key driver of Finnfjord's innovations is human capital. As the CEO, Geir-Henning says, "It is all about people. You can buy the best equipment, but you need good people to solve problems." In northern Norway, the oil industry has expanded and attracted many different businesses and employees to the region, which has enlarged the talent pool. Finnfjord attracts people by being a thought-leader in their area, while also aiming to be visible at all times e.g. at university fairs. As such, they maintain a focus on recruitment, not only when they need new employees.

Finally, Finnfjord's collaboration with UiT is driven by both party's open mindedness and acknowledgement of each other's skills (industrial and biological knowledge) as well as needs (commercialisation and publications). 


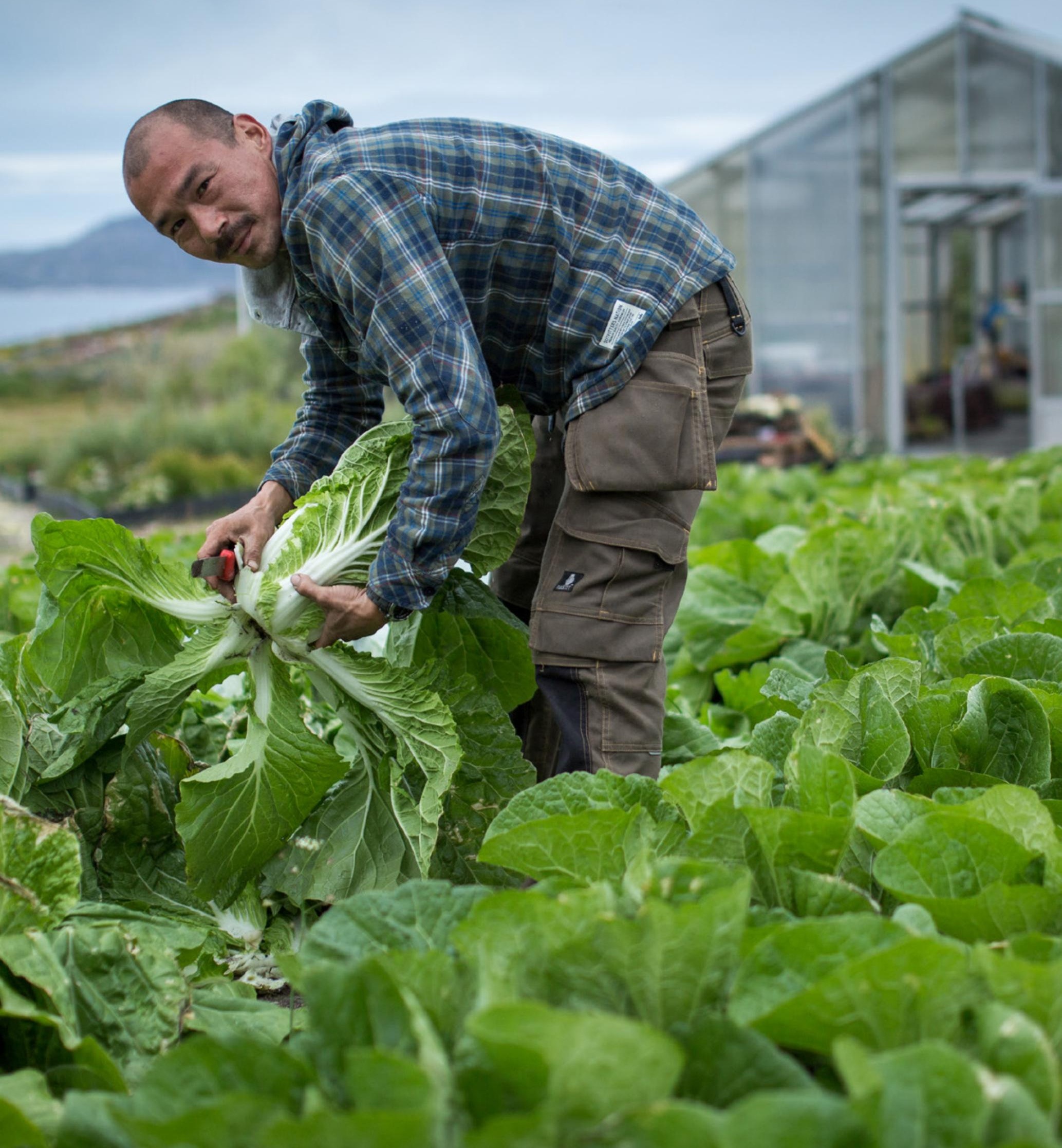


The recommendations and tools presented below revolve around opportunities to promote sustainable economic development within the Nordic Co-operation, specifically the Nordic Council of Ministers (NCM), as well as other Nordic Arctic stakeholders.

\section{Promotion of entrepreneurship education}

RECOMMENDATION: Advocate for and support the development of entrepreneurship education in the Nordic Arctic by funding projects and activities that aim to promote a local entrepreneurship culture.

$\rightarrow \quad$ Why: Some regions in the Nordic Arctic are challenged by a limited ability to start-up businesses, although opportunities and support are present. With increased global competition and reduction in primary employment opportunities, entrepreneurship is seen as a major engine for job creation and economic growth, and thereby a key to developing the Arctic.

$\rightarrow \quad$ What: To ensure a foundation of entrepreneurial and innovative activities in the Nordic Arctic, focus should be on strengthening entrepreneurship education activities informed by the local culture and population, and advocating for the development of national strategies related to this.

$\leftarrow \quad$ Harvesting fresh lettuce

in South Greenland.

Photo: Mads Pihl / Visit

Greenland

$\rightarrow \quad$ Who: Entrepreneurship education is already included in the European Commission's Entrepreneurship 2020 Action Plan and the Communication on Rethinking Education. There could be a role to play for the EU in terms of facilitating the advancement of entrepreneurship education in the Arctic. Because only Sweden, Finland, and the Kingdom of Denmark (though not Greenland and Faroe Islands) are members of EU, there is room for NCM to play a role in this regard. Specifically, the Nordic Council of 
Ministers for Education and Research (MR-U) has the possibility to lead the facilitation of promoting entrepreneurship education by supporting specific projects, disseminate information, and facilitate best practice exchange between the Nordic Arctic regions. MR-U has had entrepreneurship education as a specific focus in its programme since 2015 , and activities related to entrepreneurship education in the Arctic can be integrated into some of its currents projects. For example, the MR-U Nordplus education programme covers all the Nordic Arctic countries and has projects for all education levels including teachers. MR-U's efforts also have the potential to take place in collaboration with the Arctic members of the organisation JA Europe, who work specifically with entrepreneurship education and are present in all Nordic Arctic regions, including Greenland and the Faroe Islands. ${ }^{18}$ Allowing for a Nordic Co-operation initiative concerning entrepreneurship and innovation in the Arctic has the potential to achieve positive synergies between the Nordic Arctic regions that have different levels of entrepreneurship but share similar Arctic conditions.

$\rightarrow \quad$ Next steps: To promote the agenda and understanding of entrepreneurship education in the Arctic regions, a more in-depth understanding of local cultural needs related to entrepreneurship education is needed. This could be developed through analyses in which demand, need, and cultural understandings of entrepreneurship are uncovered in each Nordic Arctic region. This could potentially be done in collaboration with the local entrepreneurship organisations.

\section{Collaborative platforms to promote an innovative Arctic}

RECOMMENDATION: Facilitate and create cross-border collaborative platforms between Arctic areas to improve innovative business development and attract growth capital to the Arctic region.

$\rightarrow \quad$ Why: The Nordic Arctic region is often considered home to small and scattered markets, and thus attracts limited attention in terms of business developments and investments. Nevertheless, the Nordic Arctic market offers various opportunities related to its population, Arctic-specific resources, competitive gaps in certain industries and regions, and a unique Arctic cultural heritage.

$\rightarrow \quad$ What: To utilise the full potential of the offerings of the Nordic Arctic, it is important to bring the Nordic Arctic regions closer together by facilitating cross-border collaboration. Cross-border 
collaboration has the benefit of leveraging each region's strength and enables the creation of a stronger and more diversified business environment. Moreover, collaboration across borders creates a platform to brand the Nordic Arctic region (Atlantic and/ or European) as a single market for investments and business development. As "outside" investors and companies are often not interested in individual Arctic cities or smaller regions, many Arctic companies lack a larger branding platform to promote local business opportunities.

$\rightarrow \quad$ Who: Projects related to cross-border collaboration in entrepreneurship and innovation could be part of the NCM cross-border work agenda. It could also be part of NORA's (Nordic Atlantic Co-operation) work with innovative regions and development in bioeconomy and tourism. The work could emphasise cross-border collaborations, or Nordic Innovation, that specifically engage with cross-border trade and innovation, and has the potential to add a specific Arctic perspective. Finally, the work can also be driven by AEC, who work to establish strong market connections between the Arctic states, and who has an extensive network of Arctic businesses that can be leveraged in cross-border collaborations.

$\rightarrow \quad$ Next steps: To facilitate this development, Arctic stakeholders could consider engaging in dialogue with each other and organisations such as Nordic Innovation, and mapping already established cross-border platforms to uncover comparative strengths and opportunities for collaborative actions and partnerships. Moreover, cross-border business associations like AEC could play a role in facilitating connections between research and business platforms across borders, and potentially facilitate an Arctic investment branding image.

EXAMPLE: Recently Oulu, Luleå, and Tromsø have started to collaborate across the borders to establish an Arctic Innovation Hub. The project seeks to exploit Oulu's model for collaboration and talent management, Luleå's understanding of the commercialisation process, and Troms $\varnothing$ 's understanding and vision of Arctic opportunities and challenges. Although still in its initial phases, the project has the potential to increase the possibilities for new, multidisciplinary innovations by merging eco-systems with complimentary competitive advantages. Moreover, the collaboration has the potential to create what can be called an Arctic Valley where it is possible to gain access to all Arctic areas in Finland, Sweden, and Norway through any region or node of the hub. This can also be done on a smaller scale, like in northern Sweden where the city of Lulea plays a leading role in branding the northern region of Norrbotten as a whole instead of only branding the city. 


\section{Tools}

Challenge: A perceived reluctance by investors in the "south" to invest in the Arctic areas, as the areas are often perceived as unattractive in terms of profit economically and socially.

$\rightarrow \quad$ Tool: Dedicate time and money to invite investors to the Arctic, to see the potential of the specific business opportunities and the Arctic environment in general. This can be done in collaboration with various companies and include several company visits to show the diversity of opportunities. In addition, this may help decrease the perceived distance to the Nordic Arctic market.

Challenge: Integrating entrepreneurship education in primary and secondary schools.

$\rightarrow \quad$ Tool: Focus on developing ready-to-use materials, exercises, and programmes with support from the local member of JA World (organisation focusing on entrepreneurship education), taking a point of departure from the local community and people.

$\downarrow \quad$ Photo: Scanpix

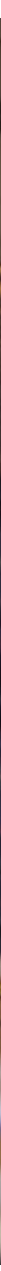




\section{CROSS-CUTTING ISSUE ACROSS THE ARCTIC BUSINESS ANALYSIS}

Desk research, case studies, and interviews have uncovered a variety of recommendations and practical tools to promote sustainable economic development for each focal area in the Arctic. These are presented in the individual reports, this one focusing on entrepreneurship and innovation. However, the study also reveals a cross-cutting issue related to Arctic-specific data related to business development. Hence, presented below is a cross-cutting recommendation on data collection and dissemination

\section{A need for Arctic-specific data}

RECOMMENDATION: Promote and support a regular collection and dissemination of Arctic specific data related to business and societal development within the Nordic region by supporting national and Nordic statistical offices in data collection and dissemination or Arctic specific data gathering projects.

$\rightarrow \quad$ Why: The Nordic Arctic region offers great potential for business development but has limited Nordic Arctic-specific data to uncover the conditions in which companies operate, social and business opportunities and challenges, resources, future investment 
opportunities, as well as other aspects of the Arctic business environment. The limited data makes it challenging for stakeholders such as businesses, academics, governments, authorities, and media to engage in more nuanced and accurate discussion on the Arctic-specific needs in business development.

$\rightarrow \quad$ What: There is a need to supplement existing statistical information with systematic and recurring information gathering to develop knowledge of the Arctic specific socio-economic developments and business opportunities.

$\rightarrow \quad$ Who: To strengthen and promote the collection and dissemination of Arctic specific data, the Nordic Co-operation could consider supporting the expansion and long-term sustainability of projects like Business Index North, and ensuring knowledge and awareness of the data by including it in the Nordic Statistical Bank.

$\rightarrow \quad$ Next steps: To promote Arctic-specific data, the national statistical offices or the Nordic Statistical Bank could reach out to the Arctic data collection projects e.g. Business Index North to discuss possible collaborations on how to collect and disseminate data on the Arctic. Furthermore, a dialogue with Arctic business clusters, like the AEC, could be initiated to map the specific information needed.

EXAMPLE: Arctic-specific data gathering e.g. include the Arctic Business Forum Yearbook developed by Lapland Chamber of Commerce, the Economy of the North (ECONOR) publication by statistics Norway, and the Business Index North project implemented mainly by High North Center at Nord University Business School in Norway in Bodø. The Yearbook presents an overview of certain European High North investments and business developments, and discusses actions to be taken to overcome barriers of business and trade. It also presents data on specific investment opportunities and projects. The Business Index North initiative is a project that runs from November 2015 to December 2018, and is developed through a strategic partnership between academic and research organizations, authorities, and commercial partners from Norway, Russia, Finland, and Sweden. It presents knowledge and statistics on the northern areas of Norway, Sweden and Finland but will gradually expand its analysis to cover the northern regions of Russia, USA, Canada, Denmark (Greenland), and Iceland. ECONOR presents an overview of the circumpolar Arctic economy, including traditional production activities of indigenous peoples, and has been published three times since 2006. 


\section{METHODOLOGY}

\section{Objectives \& Definitions}

The overall goal of this study is to provide a better understanding of the Nordic Arctic business environment with a focus on sustainable economic activities; and to generate practical recommendations to the Nordic co-operation and other Arctic actors on increasing economic activity in the Nordic Arctic. To this end, the research scope includes four focal areas selected by the steering group as areas of particular interest for sustainable business development in the Nordic Arctic. The Nordic Arctic and the four focal areas are defined below.

The Nordic Arctic is defined as the states of Iceland, Norway, Finland, Sweden and the countries Faroe Islands and Greenland (part of The Kingdom of Denmark). ${ }^{19}$ The study will include an overall analysis of the areas mentioned, but for Sweden, Norway, and Finland emphasis will be placed on the northern regions of these countries.

\section{Entrepreneurship and innovation}

$\rightarrow \quad$ Entrepreneurship is when actions take place on the basis of opportunities and good ideas, and are translated into economic, social and/or cultural value for others. ${ }^{20}$ Along similar lines, innovation is the process of promoting changes in technologies, products, or administrative practices. It is important, however, that the understanding of entrepreneurship, innovation, and an entrepreneurial mind-set is embedded within regional and cultural contexts.

Public-private partnerships (PPPs) and business co-operation

$\rightarrow \quad$ PPPs are an interaction between public and private institutions for the delivery of pre-defined services. The aim is to provide public service delivery from a mutually beneficial partnership, though the partnership remains founded in public oversight. ${ }^{21}$ 
$\rightarrow \quad$ Business co-operation is, in this report, defined as industry clusters, where the seminal definition is a "...geographical concentration of interconnected companies, specialised suppliers, and associated institutions (e.g., universities, standards agencies, trade associations) in a particular field that compete but also co-operate." This definition is combined with the European Cluster Excellence programmes labelling to specify the clusters. ${ }^{22}$

\section{Bioeconomy}

$\rightarrow \quad$ Bioeconomy consists of the management of renewable biological resources and their conversion into food, livestock feed, bio-based products, and bioenergy via innovative and efficient technologies. It means using biomass intelligently and creatively through the four pillars of bioeconomy: collaborate, circulate, upgrade, and replace. $^{23}$

\section{Creative and cultural industries}

$\rightarrow \quad$ Creative and cultural industries encompass a broader range of activities that include creative and cultural production. In an Arctic context, it often emphasises human creativity as a way to leverage cultural heritage and translate it into a business. ${ }^{24}$

\section{Research Approach}

To achieve the aim of this study, a three-phase research approach was developed as illustrated below.

\begin{tabular}{|c|c|c|}
\hline $\begin{array}{l}\text { Mapping \& } \\
\text { Cross-Analysis }\end{array}$ & Case Studies & $\begin{array}{l}\text { Findings \& } \\
\text { Recommendations }\end{array}$ \\
\hline $\begin{aligned} \rightarrow & \text { Mapping key policies } \\
\rightarrow & \text { Mapping recent economic } \\
& \text { activity } \\
\rightarrow & \text { Cross-analysis of focal areas } \\
\rightarrow & \text { Identification of drivers and } \\
& \text { enablers }\end{aligned}$ & $\begin{aligned} \rightarrow & \text { Case study selection } \\
\rightarrow & \text { Development of case studies } \\
\rightarrow & \text { Identification of drivers and } \\
& \text { enablers }\end{aligned}$ & $\begin{array}{l}\rightarrow \text { Stakeholder review of findings } \\
\text { an hypotheses } \\
\rightarrow \text { Development of recommen- } \\
\text { dations }\end{array}$ \\
\hline
\end{tabular}




\section{Mapping \& Cross-Analysis}

The mapping sought to identify policies and recent economic activity within the focal areas through extensive desk research. The key insights from the mapping were consolidated in a cross-analysis framework that assessed and correlated the level of policy support with the level of economic activity. The combination of factors indicated opportunities concerning policy and economic activity and gaps for sectors in each focal area. This generated hypotheses on enabling and constraining factors, as well as developed an overview of business development potential in the Nordic Arctic. Considering the challenge in quantifying and measuring the topics of this study, a score-based method was developed based on a qualitative assessment of the policies promoting economic activity and available data on actual economic activity in the Nordic Arctic. The multiple scoring method relied on a pre-defined assessment scale and estimations from various project collaborators.

\section{Case Studies}

Enabling and constraining factors identified in the cross-analysis were further examined through case studies of selected businesses, organisations, and projects identified during the desk research and the cross-analysis. Case studies were selected based on their ability to enrich the analysis of gaps and enablers, and ability to scale potential learnings to other businesses, industries, and potentially other Arctic areas.

\section{Findings \& Recommendations}

Findings and hypotheses from the mapping, cross-analysis, and case studies were assessed and reviewed by several stakeholders in the Nordic Arctic region for evaluation, further development, and final assessment. Finally, knowledge and conclusions were synthesised to develop recommendations on ways in which the Nordic Co-operation, specifically Nordic Council of Ministers (NCM), and other Arctic actors can support specific initiatives in the future to facilitate economic growth, investment, and business development in the Nordic Arctic region. 
Chiu, Richard. Entrepreneurship Education in the Nordic Countries: Strategy Implementation and Good Practices, 2012. http://www.nordicinnovation.org/Global/_Publications/Reports/2013/Entrepreneurship_Education_in_Nordics_web. pdf.

Cornell University, INSEAD, and WIPO. "The Global Innovation Index 2017: Innovation Feeding the World." Geneva, 2017.

Dodd, Sarah Drakapoulou, and Briga Chris Hynes. "The Impact of Regional Entrepreneurial Contexts upon Enterprise Education." Entrepreneurship and Regional Development, 2012.

European Commission. "Entrepreneurship Education," 2017. https:// ec.europa.eu/growth/smes/promoting-entrepreneurship/support/ education_en.

Gardiner, Ann, Matthieu Bardout, Francesca Grossi, and Sandrine Dixson-Declève. "Public-Private Partnerships for Climate Finance," 2016. https://doi.org/10.6027/ TN2015-577.

GEDI. "Global Entrepreneurship Index 2017." Washington, 2017.

High North Center. "Business Index North - A Periodic Report with Insight to Business Activity and Opportunities in the Arctic," 2017. Hintsala, Henna, Sami Niemelä, and Pekka Tervonen. "Arctic Innovation Hubs: Opportunities for Regional Co-Operation and Collaboration in Oulu, Luleå, and Tromsø." The Northern Review 45 (2017): 77-92.

Njos, R., S.-E. Jakobsen, H. Wiig Aslesen, and A. Floysand. "Encounters between Cluster Theory, Policy and Practice in Norway: Hubbing, Blending and Conceptual Stretching." European Ur- ban and Regional Studies, 2016. http://eur.sagepub.com/cgi/ doi/10.1177/0969776416655860.

Nordic Council of Ministers. "25 Cases for Sustainable Change," 2017. . A Good Life in a Sustainable Nordic Region. Nordic Strategy for Sustainable Development, 2013.

Nordic Innovation. "Nordic Entrepreneurship Check 2016." Olso, 2016.

Reffstrup, T., and S.K. Christensen. "Nordic Entrepreneurship Islands," 2017.

SchoolEducationGateway. "Entrepreneurship Education in Finland," 2015.

. "Entrepreneurship Education in Sweden," 2015.

UNESCO. "Understanding Creative Industries. Cultural Statisitcs for Public Policy-Making." Global Alliance Team, 2006, 8. http://portal. unesco.org/culture/en/ev.php-URL_ ID =29947\&URL_DO=DO_TOPIC\&URL_SECTION=-465.html. 
1 Nordic Council of Ministers, A Good Life in a Sustainable Nordic Region. Nordic Strategy for Sustainable Development, 2013. https://doi. org/10.6027/ANP2013-728.

2 T. Reffstrup and S.K. Christensen, "Nordic Entrepreneurship Islands," 2017.

3 For more details please see annex for country descriptions.

4 Definition of entrepreneurship education: Content, methods and activities that support the development of motivation, competence and experience that make it possible to implement, manage and participate in value-added processes. Ibid.

5 Nordic Innovation, "Nordic Entrepreneurship Check 2016" (Olso, 2016).

6 For more details please see annex for country descriptions.

7 The term innovation includes activities such as process, organisational, marketing, technological and product innovation.

8 SMEs are Small and Medium Enterprises and include all companies with less than 250 employees (excluding non-employer firms).

9 Cornell University, INSEAD, and WIPO, "The Global Innovation Index 2017: Innovation Feeding the World" (Geneva, 2017); GEDI, "Global Entrepreneurship Index 2017" (Washington, 2017). The GII is an aggregation of two subindexes, namely Innovation Input, measureing institutional environment, humand capital and research, market sophistication and business sophistication as well as Innovation Output, such as knowledge and technology output and creative outpounts. Similarly. the Global Entrepreneurship Index ranks entrepreneurial activity through an aggregation of indexes related to entrepreneurial attitudes (e.g cultural support, networking, start-up skills etc.), entrepreneurial activities (e.g. competition, human resource quality, opportunity startup) and entrepreneurial aspirations (e.g. high growth, new tech and new product). It is important to mention however that institutional environment is not so much a measure of economic activity as it is a precondition.

10 High North Center, "Business Index North - A Periodic Report with Insight to Business Activity and Opportunities in the Arctic," 2017.

11 The data on micro businesses cover the 'non-financial business economy', which includes industry, construction, trade and services, but not enterprises in agriculture, forestry and fisheries and the largely non-market service sectors such as education and health.

12 Richard Chiu, Entrepreneurship Education in the Nordic Countries: Strategy Implementation and Good Practices, 2012, http://www.nordicinnovation.org/Global/_Publications/Reports/2013/Entrepreneurship_Education_in_Nordics_web. pdf.

13 Ibid.; Reffstrup and Christensen, "Nordic Entrepreneurship Islands"; European Commission, "Entrepreneurship Education," 2017, https:// ec.europa.eu/growth/smes/promoting-entrepreneurship/support/ education_en.

14 Sarah Drakapoulou Dodd and Briga Chris Hynes, "The Impact of Regional Entrepreneurial Contexts upon Enterprise Education," Entrepreneurship and Regional Development, 2012.
15 SchoolEducationGateway, "Entrepreneurship Education in Sweden," 2015.

16 SchoolEducationGateway, "Entrepreneurship Education in Finland," 2015.

17 Henna Hintsala, Sami Niemelä, and Pekka Tervonen, "Arctic Innovation Hubs: Opportunities for Regional Co-Operation and Collaboration in Oulu, Luleå, and Tromsø," The Northern Review 45 (2017): 77-92.

18 Norway: http://www.ve.no/; Finland: https://nuoriyrittajyys.fi/en/; Sweden: http://ungforetagsamhet. se/; Iceland: http://ungirfrumkvodlar.is/; Faroe Island: http://faeroerne.ffe-ye.dk/; Greenland: http:// gronland.ffe-ye.dk/.

19 Incentives and opportunities related to Denmark will be mentioned in they specifically relate to Greenland or the Faroe Islands.

20 T. Reffstrup and S.K. Christensen, "Nordic Entrepreneurship Islands," 2017.

21 Ann Gardiner et al., "Public-Private Partnerships for Climate Finance," 2016, https://doi.org/10.6027/ TN2015-577

22 R. Njos et al., "Encounters between Cluster Theory, Policy and Practice in Norway: Hubbing, Blending and Conceptual Stretching," European Urban and Regional Studies, 2016, http://eur.sagepub.com/cgi/ doi/10.1177/0969776416655860.

23 Nordic Council of Ministers, "25 Cases for Sustainable Change."

24 UNESCO, "Understanding Creative Industries. Cultural Statisitcs for Public Policy-Making," Global Alliance Team, 2006, 8, http://portal. unesco.org/culture/en/ev.php-URL_ ID =29947\&URL_DO=DO_TOPIC\&URL_SECTION=-465.html. 


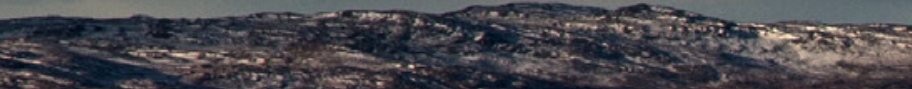




\section{D(1) AEC Voluntās}


Nordic Council of Ministers

Nordens Hus

Ved Stranden 18

DK-1061 Copenhagen K

www.norden.org

\section{Arctic Business Analysis}

- Opportunities for people, businesses and investments

In 2016, the Nordic Cooperation Ministers decided to put more emphasis on economic development in the Arctic within the Arctic Cooperation Program of the Nordic Council of Ministers.

The Nordic Council of Ministers partnered up with the Arctic Economic Council in carrying out an Arctic Business Analysis. The aim was to qualify knowledge on the business environment in the Nordic Arctic and how to take the business environment to a next level.

The analysis covers 1) Entrepreneurship and Innovations; 2) PublicPrivate Partnerships \& Business Cooperation; 3) Bio-economy, and 4) Creative and Cultural Industries.

The general findings of the analysis are:

$\rightarrow \quad$ a need for an increased collection and dissemination of Arctic specific data;

$\rightarrow \quad$ a need for strengthened cross-border business collaboration between regions and actors in the Arctic; and

$\rightarrow \quad$ a need for a positive branding of the Arctic as an attractive and sustainable market for investments and economic development. 